restored to friends, and in the course of time it died also. These two latter experiments having proved unsatisfactory, would you presume the experiment of sending children to hospital, or restoring them to friends, likely to be discontinued? The same with equal force will apply to nursing.

I see both the in- and out-patients, and am fully satisfied more could not be done than is done, not only for the benefit of the child, but also for the welfare of the mother. In conclusion, allow me to remark that the nursing system answers admirably, and that there is no real source of anxiety to the health officer, nor to anyone else who will take the trouble to understand the nature as well as the statistics of the Home.

I am, Sir, your obedient servant,

Richard Paramore

Hunter-street, Branswick-square, Sept. 13th, 1870. Medical Officer.

\section{UTILISATION OF SEWAGE.}

\section{To the Editor of The LANCET.}

SrR,-The public interest is excited on the utilisation of sewage, and I fear much that has been done will have to be undone in consequence of the ill-health that it will generate in the cattle, and in man directly and indirectly, by casting either the fluid or the solid in its impure state upon the land, vitiating the grass, and impregnating the air with noxious gases. One of the proper modes of treating it is as follows:- Erect machinery in all large towns; burn the rubbish and the solid night-soil in confined vessels, or otherwise form it into pure carbon, and purify the fluid manure by passing it through the carbon formed by the solid manure.

If you will kindly permit the insertion of this you will oblige an old subscriber: and I have not burdened you, fearing to take too large a space in your columns.

I remain, Sir, your obedient servant, George Wasmington Evans, M.R.C.S.

Reading, Sept. 17th, 1870 .

\section{SURGICAL NOTES OF THE WAR. (FROM OUR CORRESPONDENT AT DARMISTADT.)} Sept. 5th, 1870

MaNY appeals have been made through the medium of the English newspapers for surgeons who are willing to proceed to the seat of war, where they are said to be much wanted. Now I can state from personal experience that this is not the case to anything like the extent represented. No one ought to come out to Germany unless he has a perfect colloquial acquaintance with the language, and even then it is extremely doubtful if he will be required, for on the German side they appear to be plentifully supplied with medical attendance. In company with three other medical men sent out by the Prussian Embassy in London, I was sent from Mayence to the head-quarters of the army in the front of Metz, but only to have our services peremptorily declined by Dr. Weber, Medical Inspector-General to the 2nd Army, on the ground that we could not speak German fluently; and if, on returning to Mayence, we had not met from the authorities there with more kindness and appreciation than we did from our professional brother at the front, ere this we should have returned to England without having had charge of a single case. As it is, we have now been nearly three weeks in Germany, and are only now getting into harness. Seemingly we are likely to be settled here till the termination of the war, and as perhaps it might interest the readers of The LANCET to have from time to time a short account of any interesting cases, and as in a hospital containing over two hundred gunshot wounds there are sure to be many such, I will endeavour to supply this, and anything relating to hospital administration \&c. that it may be in my power to mention.

The hospitals here, which are nearly all temporary, make np collectivily from six to seven hundred beds, but the number of sick and wounded at present occupying them is not more than four hundred. A large increase may be expected when those wounded in the late battles before Metz arrive. The hospital of the greatest extent is the one situated on what are called the Orangeries, or gardens of the
Grand Duke, and this contains at present between two and three hundred beds. It is supported and managed by the local Hülfs Verein, or Association for the Relief of the Sick and Wounded, of the Ladies' Committee of which H.R.H. the Princess Alice is president; and in her case this is not merely an honorary position. Oi the ccntrary, she takes. the superintendence of all the work, visiting the hospitals twice a day ; indeed, in activity and business-like habits she is an example to all, and that, too, nnder cireumstances in which rest would be quite excusabie. The writer had an opportunity of seeing her kindness to the patients, and how much it was appreciated by them in a visit he inade to the hospital with her Royal Highness. 'To her interest are we mainly indebted for the privilege of having under our charge one of the pavilions of the hospital; although in fairness we must state that in this matter Herr Weber, the President, and other members of the Hülfs Verein, have also met us in the most cordial manner.

The buildings devoted to hospital uses are, firstly, two old exections which answered formerly for greenhouses, although built mostly of stone. They are high in the roof, and great efforts have been made to provide for ventilation. Besides being at present overcrowded, they are not so well suited for hospital purposes as the other buildings $I$ am about to mention. These are pavilions, built with wooden roofs, and sides partly wood and partly canvas, and with ample provision for light and ventilation. They possess the advantages besides of containing only sirteen beds each, and of being detached and scattered through the gardens. They are seven in number, and two more are in course of completion. These buildings, if they were built in a little more substantial manner, and consequently more. suited for winter weather, would be, to my thinking, the beau ideal of hospital arrangement; and already the German surgeons notice a marked superiority in the results obtained in these tents or barracks, as they are called, compared with those in the permanent buildings. The offices, consisting of kitchen, dead-house, post-mortem room, as well as the operating theatre, are all detached, but are well supplied with every modern appliance ; indeed, it is astonishing to see all so well arranged in so short a time, and is only another proof of the great capability of organisation and sense of method inherent in the German mind. The medical staif has at its head Professor Lutter, of Berne, a pupil of Langenbeck, as consulting surgeon, and the other surgeons have each charge of about sixteen beds, all the medical men of the town taking their share. Prof. Lutter has several young Swiss surgeons with him. The nursing is amply provided for, great part being undertaken by the Sisters of Charity, and the rest is under the immediate superintendence of the ladies of the Hülfs Verein. As all is done by voluntary effort, the great thing required is money, and that is the best way in which assistance can be sent from England, for it can procure everything else. If any one should feel inclined to help in that way, I hope he will not forget the English Ward of the Orangeries Hospital at Darmstadt.

And now a word or two as to the patients. In going round the wards one notices that the wounds are nearly all inflicted by shots from the chassepot; some few by the mi trailleuse, but rarely indeed by the shell, those by the latter being usually too severe to allow of the sufferers being brought so far as this. Another thing is the great preponderance of wounds of the extremities, especially of the right elbow and arm, arising from the shot striking when the soldier is in the firing position. Compound fractures of the long bones or their extremities are very common, and in some cases they are extremely comminuted. One case was mentioned where, in excising an elbow, it was necessary to remove thirty-three fragments of bone. The operations mostly required are amputations of both upper and lower extremities, and excisions of joints; that of the elbow very common indeed; that of the knee has been tried three or four times, but does not appear to be in much favour. Then ligature of the arteries is frequently needed for wounds implicating them secondarily. Of course primary cases are treated on the field. The surgeons are extremely conservative in their surgery, making every possible effort to save the limbs of their patients, sometimes perhaps erring on that side. Carbolic acid is $\mathrm{u}=\mathrm{ed}$, but only as a lotion, and not after Lister's plan; but I hope to have an opportunity of trying it upon gunshot wounds. Pyæmia is 